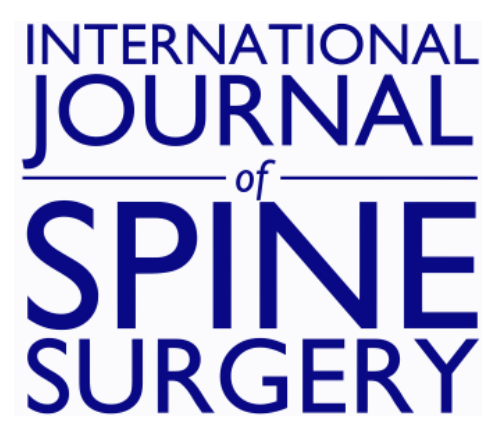

\title{
Comparison of Preoperative Pedicle Screw Measurement Between Computed Tomography and Magnet Resonance Imaging
}

TAREK OMAR PACHA, MOHAMED OMAR, TILMANN GRAULICH, EDUARDO SUERO, BENNET MATHIS SCHRÖDER, CHRISTIAN KRETTEK and TIMO STUBIG

Int J Spine Surg 2020, 14 (5) 671-680

doi: https://doi.org/10.14444/7098

http://ijssurgery.com/content/14/5/671

This information is current as of April 26, 2023.

Email Alerts Receive free email-alerts when new articles cite this article. Sign up at:

http://ijssurgery.com/alerts

The International Journal of Spine Surgery

2397 Waterbury Circle, Suite 1,

Aurora, IL 60504, Phone: +1-630-375-1432 


\title{
Comparison of Preoperative Pedicle Screw Measurement Between Computed Tomography and Magnet Resonance Imaging
}

TAREK OMAR PACHA, MD, Dr med, ${ }^{1}$ MOHAMED OMAR, MD, PD Dr med, ${ }^{1}$ TILMANN GRAULICH, MD, Dr med, ${ }^{1}$ EDUARDO SUERO, MD, Dr med, ${ }^{2}$ BENNET MATHIS SCHRÖDER, MD, ${ }^{1}$ CHRISTIAN KRETTEK, MD, PD Dr med, ${ }^{1}$ TIMO STUBIG, MD, PD Dr med ${ }^{1}$

${ }^{I}$ Trauma Department, Hannover Medical School(MHH); Lower Saxony, Germany, ${ }^{2}$ Department of General, Trauma and Reconstructive Surgery, University Hospital, LMU Munich, Munich, Germany

\begin{abstract}
Background: Pedicle screw fixation is commonly used in the treatment of spinal pathologies. While the biomechanical factors that affect bone fixation have been frequently described, questions remain as to which imaging modality is the ideal medium for preoperative planning. Due to its perceived superiority in assessing bony changes, computed tomography (CT) scan is assumed to be the gold standard for preparative planning, and we hypothesize that magnetic resonance imaging (MRI) is sufficiently accurate to predict screw length and diameter compared to CT.

Methods: We retrospectively measured the length and diameter of vertebral bodies in the lumbar region in both MRI and CT and tested for differences between the modalities as well as for confounding effects of age, sex, and the presence of spondyloarthrosis.

Results: We found a significant difference in pedicle screw length between CT and MRI measurements for both sides. For the left pedicle, the mean difference was $1.89 \mathrm{~mm}(95 \%$ confidence interval $[\mathrm{CI}]-3.03$ to $-0.75 ; P<.002)$, while for the right pedicle, the mean difference was $2.05 \mathrm{~mm}(95 \% \mathrm{CI}-3.27$ to $-0.84 ; P=.001)$. We also found a significant difference in diameter measurements between CT and MRI for the left pedicle $(0.53 \mathrm{~mm} ; 95 \%$ CI 0.13 to $0.93 ; P=.011)$ but not for the right pedicle $(0.36 \mathrm{~mm} ; 95 \% \mathrm{CI}-0.06$ to $0.78 ; P=.094)$. We identified no significant effect of sex, age or spondyloarthrosis on the results $(P>.05)$.

Conclusions: Pedicle screw planning measurements were more accurate using CT images compared to MRI images. CT scan remains the gold standard for pedicle screw planning in trauma surgery. When using MRI images, the surgeon should be aware of the differences in screw length and diameter compared to CT in order to avoid intra- and postoperative risks.
\end{abstract}

Lumbar Spine

Keywords: pedicle screw, spondylodesis, preoperative planning

\section{INTRODUCTION}

Posterior spinal fusion is an important tool in the treatment of patients with spinal trauma or with degenerative disorders like spinal stenosis or spondylolisthesis. ${ }^{1-9}$ Numerous studies have been aimed at quantifying the ideal biomechanical properties of the implants required to maximize pullout resistance, ${ }^{10-14}$ but the optimal trajectory angle for placing pedicle screws remains unclear. While some authors aim for a trajectory that results in the longest possible screw, others favor a position parallel to the pedicle wall, accepting a decreased insertion depth. ${ }^{10,11,13}$ Despite disagreements in an ideal trajectory angle, there is consensus that the main focus should be in placing the pedicle screw within the safe corridor to prevent nerve root or spinal cord injury. ${ }^{10,15}$

Aside from the trajectory angle, the diameter of the screw seems to be more important than the depth of the screw for improving pullout strength. ${ }^{10,11,14}$ Further pullout resistance is achieved by implanting the screws parallel to the cover plate of the vertebra, ${ }^{12,13,16}$ but the definitive size of the right screw finally depends on the anatomy of the patient and on the availability of the specific screw sizes. ${ }^{10}$

Considering these conditions, preoperative planning and measurement of size and direction of the pedicle is highly recommended. ${ }^{11,15}$ To date, the gold standard imaging modality for the preoperative 
planning of most pedicle screw placement indications is computed tomography (CT), especially in trauma. ${ }^{17,18}$ Its main advantage is the 3 -dimensional visualization of the spine, which offers improved appreciation of the complex bony structures of the spine, allowing for correct classification of the fractured vertebra. ${ }^{18-20}$

But the situation is different in the assessment of degenerative changes. In this case, the major focus is the visualization of the spinal cord, nerve roots, spinal stenosis, and intervertebral discs, where magnetic resonance imaging (MRI) provides superior information compared to $\mathrm{CT} .^{8,9}$

However, because spondylodesis also plays a major role in the treatment of these pathologies, ${ }^{4-6}$ an additional CT scan is usually performed despite confirmed diagnosis by MRI. It remains unclear whether an MRI provides a sufficiently precise measurement ability for the planning of the screw size compared to CT.

In the current study, we aimed to assess the ability of MRI to predict screw size for dorsal instrumentation. We hypothesized that MRI-based screw length and diameter predictions would be comparable to those made using CT scans.

\section{MATERIALS AND METHODS}

This study was approved by our institution's ethics committee. We obtained paired CT and MRI imaging data sets of patients who were treated with invasive spinal procedures for both trauma and degenerative disease indications at our institution between January 2017 and April 2019. To be included in the study, patients had to have received both CT and MRI imaging. Due to the retrospective nature of the study, the MRI and CT devices used are heterogeneous. For the MRI, the resolution varies from 1.5 to 3 Tesla. We excluded patients under 18 years of age, patients with previous osteosynthesis material in the region of interest, patients with tumor disease or with spinal infection in the target anatomic region, patients with missing or incomplete data, and cases with poor-quality imaging data.

In total, the paired CT and MRI data sets of 72 vertebral bodies and 144 pedicles were analyzed. One investigator performed all measurements (Figure 1) using standard planning software (Visage 7.1, Visage Imaging, GmbH, Berlin, Germany). First, the data for the CT and MRI scans of each patient were loaded onto the imaging software. Measure-

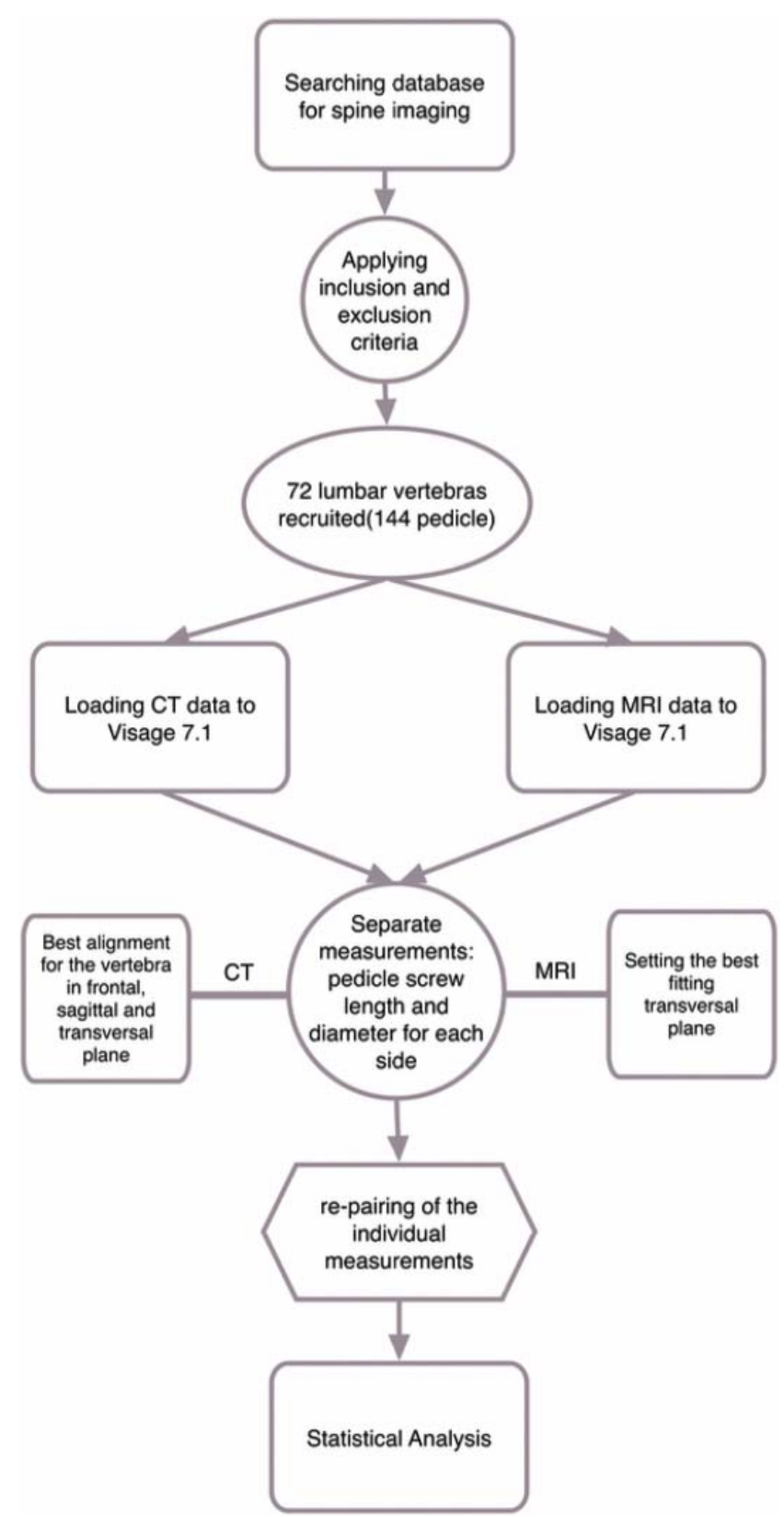

Figure 1. Flowchart study procedure.

ments of CT and MRI scans were performed in randomized order, with the investigator blinded to the patient's identity.

To conduct CT scan measurements, the vertebral body was set in the sagittal plane. We then aligned the vertebral body in all 3 important view planes: coronal, sagittal, and axial. The axial plane was placed exactly parallel to the endplate of the vertebral body and exactly in the middle of the pedicle (Figure 2). We drew a line in the dorsoventral trajectory running through the pedicle and ending at the intersection with the ventral corticales of the vertebral body. This line marks the right 


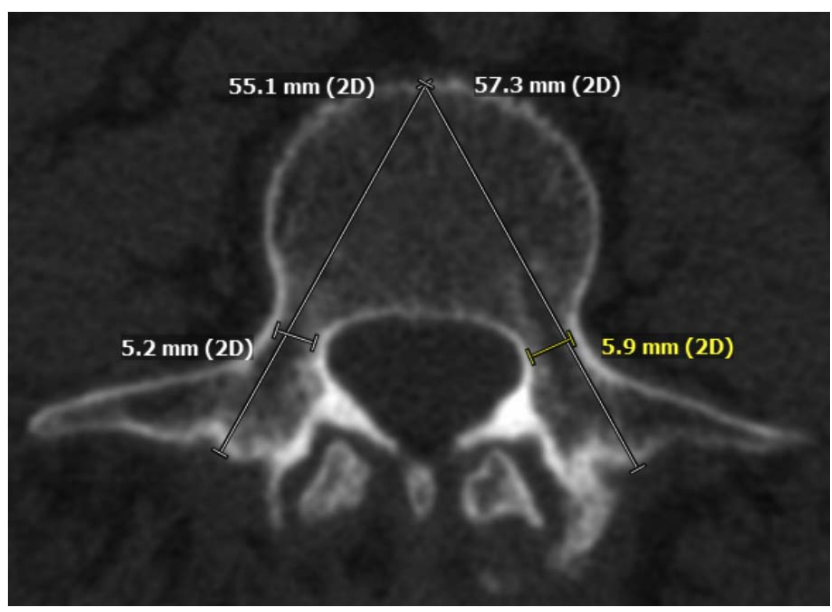

Figure 2. Transversal cutting, computed tomography (lumbar vertebra 3).

corridor for the implant and its expected length. Next, a second measurement line was drawn at a right angle to the dorsoventral line at the narrowest point of the pedicle. This process was repeated for the contralateral side.

\section{MRI}

MRI measurements were conducted in an analogous way, in both T1 and T2 weighted images. Due to the inherent technical characteristics of MRI imaging, it was not possible to adjust the different cutting planes through the vertebral body in exactly the same fashion as we did with CT scans. In order to get a cutting plane parallel to the endplate, the entire geometry has to be tilted in relation to the patient on the MRI data set. This is possible only when carrying out the examination and cannot be retrospectively digitally reconstructed. This results in potentially diminished precision but reflects the context on real clinical conditions. We set the vertebral body in all 3 planes with the best approximation to the optimal screw position. Actual measurements were carried out in exactly the same way as we did using CT images (Figure 3).

\section{STATISTICAL METHODS}

We conducted paired Student $t$ tests to identify significant differences in measurements between the two imaging modalities. We also conducted analysis of variance tests to identify any possible confounding effects of age, sex, and the presence of spondylarthrosis on the results and drew interaction plots to rule out any hidden interactions. The

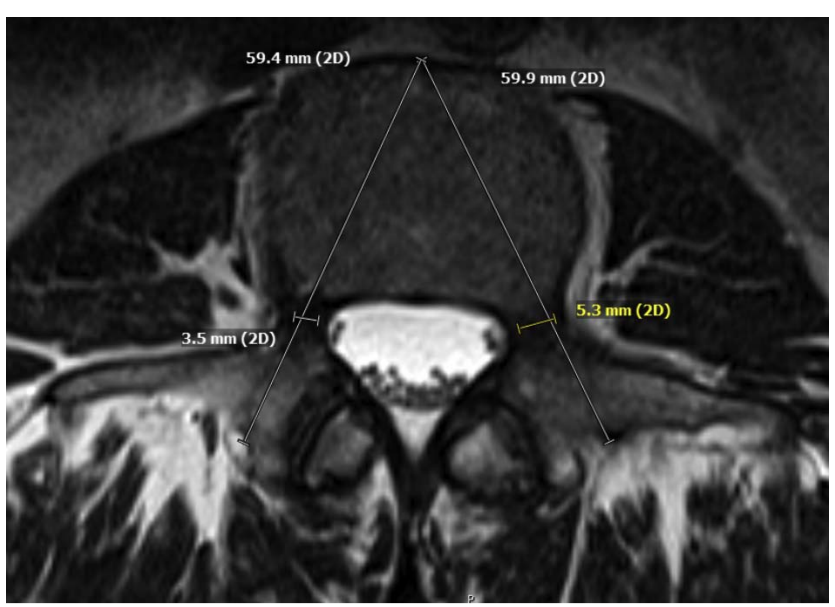

Figure 3. Transversal cutting, magnetic resonance imaging (lumbar vertebra 3).

analyses were conducted using SPSS v26 (IBM, Armonk, New York) with $\alpha$ set to 0.05 for all tests.

\section{RESULTS}

\section{Demographic Data}

There were 16 male and 56 female patients, with ages ranging from 41 to 85 years (Tables 1 and 2). In total, 51 out of 72 vertebrae showed signed of spondyloarthrosis.

\section{Pedicle Measurements}

We found a significant difference in pedicle screw length between CT and MRI measurements for both sides (Table 3). For the left pedicle, the mean difference was $1.89 \mathrm{~mm}(95 \%$ confidence interval $[\mathrm{CI}]-3.03$ to $-0.75 ; P<.002$; Table 4 ), while for the right pedicle the mean difference was $2.05 \mathrm{~mm}(95 \%$ CI -3.27 to $-0.84 ; P=.001$; Table 5).

We also found a significant difference in diameter measurements between CT and MRI for the left pedicle $(0.53 \mathrm{~mm} ; 95 \%$ CI 0.13 to $0.93 ; P=.011$; Table 6$)$ but not for the right pedicle $(0.36 \mathrm{~mm} ; 95 \%$ CI -0.06 to $0.78 ; P=.094$; Table 7 ). We identified no significant effect of sex, age, or spondyloarthrosis on the results $(P>.05)$ for the left pedicle in length and the diameter of both sides (Table 8). The univariate analysis of variance shows a significant influence of age and spondyloarthritis in relation to the length of the right pedicle. (Tables 9-12). The interaction plots graphically show an intersection of spondylarthrosis and gender, but the influences remain insignificant for all parameters (Tables 912). 


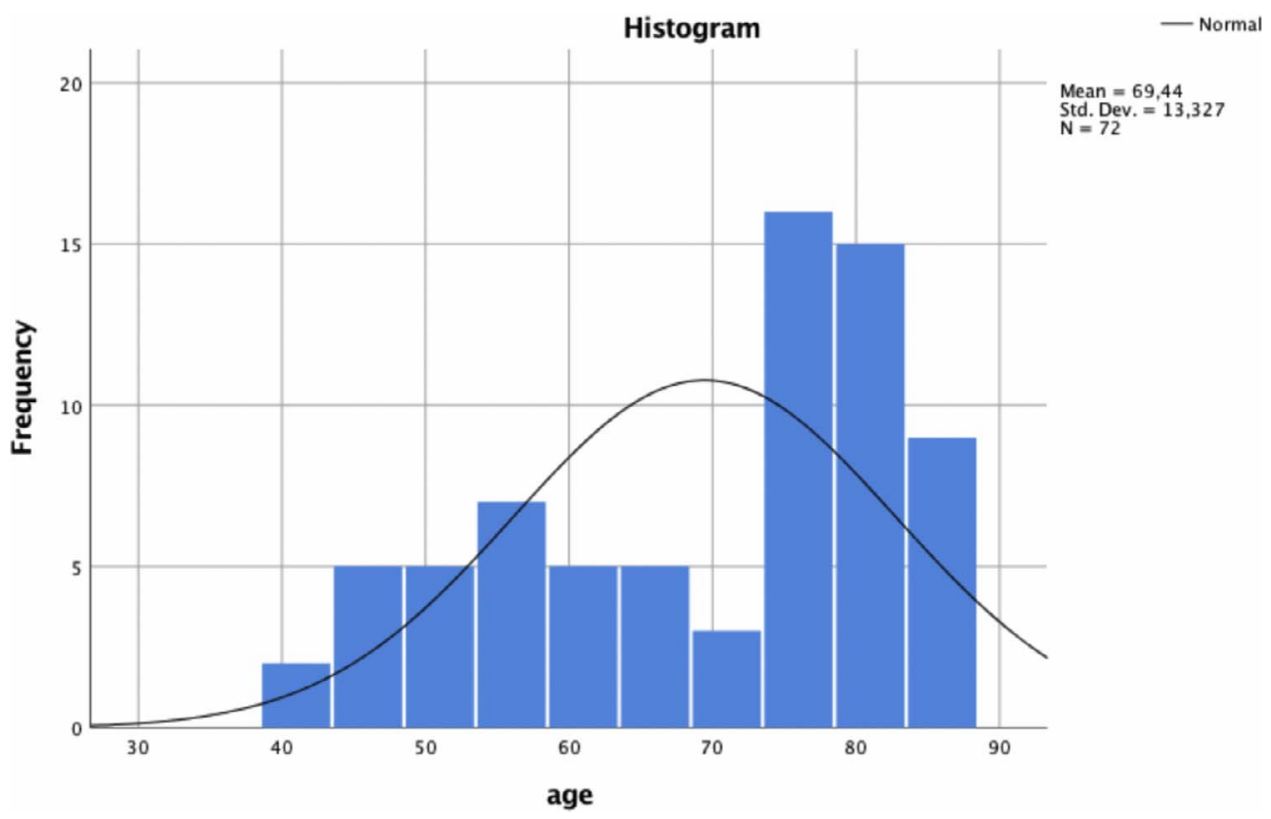

\section{DISCUSSION}

CT imaging is currently the gold standard for assessing the bony structure of the spine, ${ }^{17,18,21}$ having its greatest impact in assessing for pathological changes in fractures, osteolysis, spinal stenosis, and dysmorphic pedicles. ${ }^{17}$ MRI imaging, on the other hand, is routinely used to assess soft-tissue, vascular, and spinal cord abnormalities. To the best of our knowledge, no previous study has directly compared the effectiveness of MRI imaging in the preoperative planning of pedicle screw placement.

Table 2. Baseline character.

\begin{tabular}{|l|l|l|}
\hline \multirow{3}{*}{ Age - yr } & \multicolumn{2}{|c|}{ Baseline character } \\
\cline { 2 - 3 } & mean & \\
\cline { 2 - 3 } Sex - no. & range & 69,44 \\
\cline { 2 - 3 } & Male (\%) & $41-85$ \\
\cline { 2 - 3 } & Female (\%) & $16(22,2)$ \\
\hline $\begin{array}{c}\text { Spondylarthrosis } \\
\text { - no. }\end{array}$ & $1 \%)$ & $56(77,8)$ \\
\cline { 2 - 3 } & O(\%) & $51(70,8)$ \\
\hline V1 - no. & Count (\%) & $21(29,2)$ \\
\hline V2-no. & Count (\%) & $16(22,3)$ \\
\hline V3-no. & Count (\%) & $13(18,1)$ \\
\hline V4-no. & Count (\%) & $14(19,4)$ \\
\hline V5-no. & Count (\%) & $13(18,1)$ \\
\hline & & $16(22,2)$ \\
\hline
\end{tabular}


Table 3. Distribution of vertebra (lumbar 1-5).

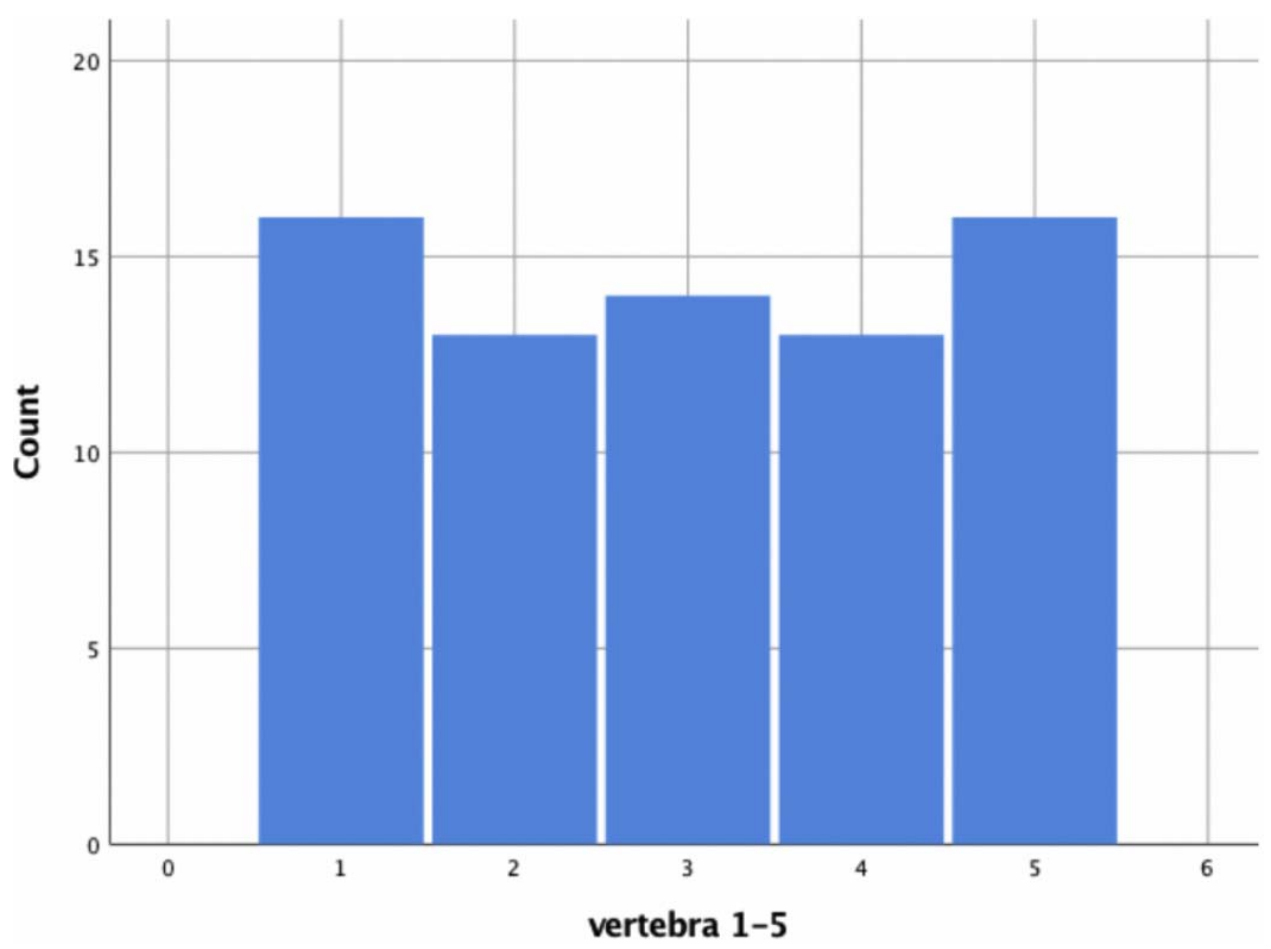

In the current study, we measured the length and diameter of 144 pedicles of 72 lumbar vertebrae using both CT and MRI images. The main finding of the current study was that CT-based preoperative screw planning measurements were significant- ly more accurate using CT compared to MRI images.

Three of the 4 most important study parameters demonstrated significant measurement differences between CT and MRI scans. In our analysis,

Table 4. Mean difference in length (left pedicle).

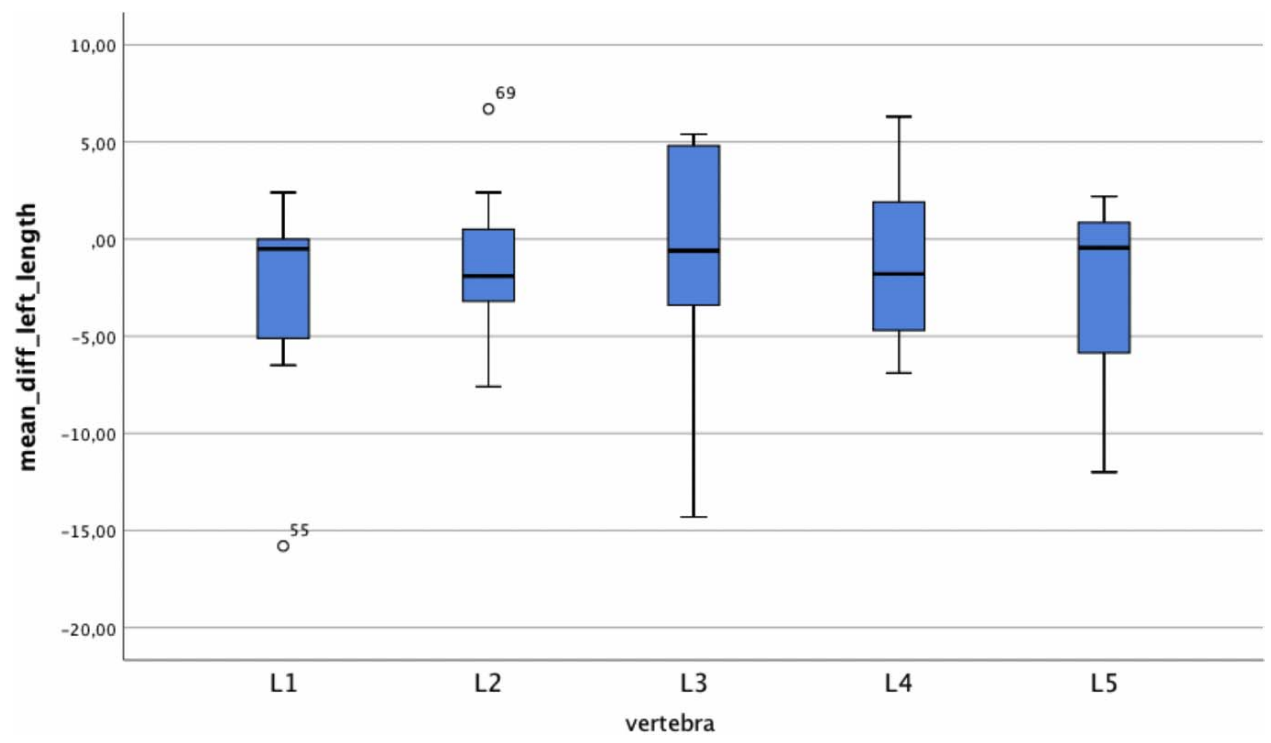


Table 5. Mean difference in length (right pedicle).

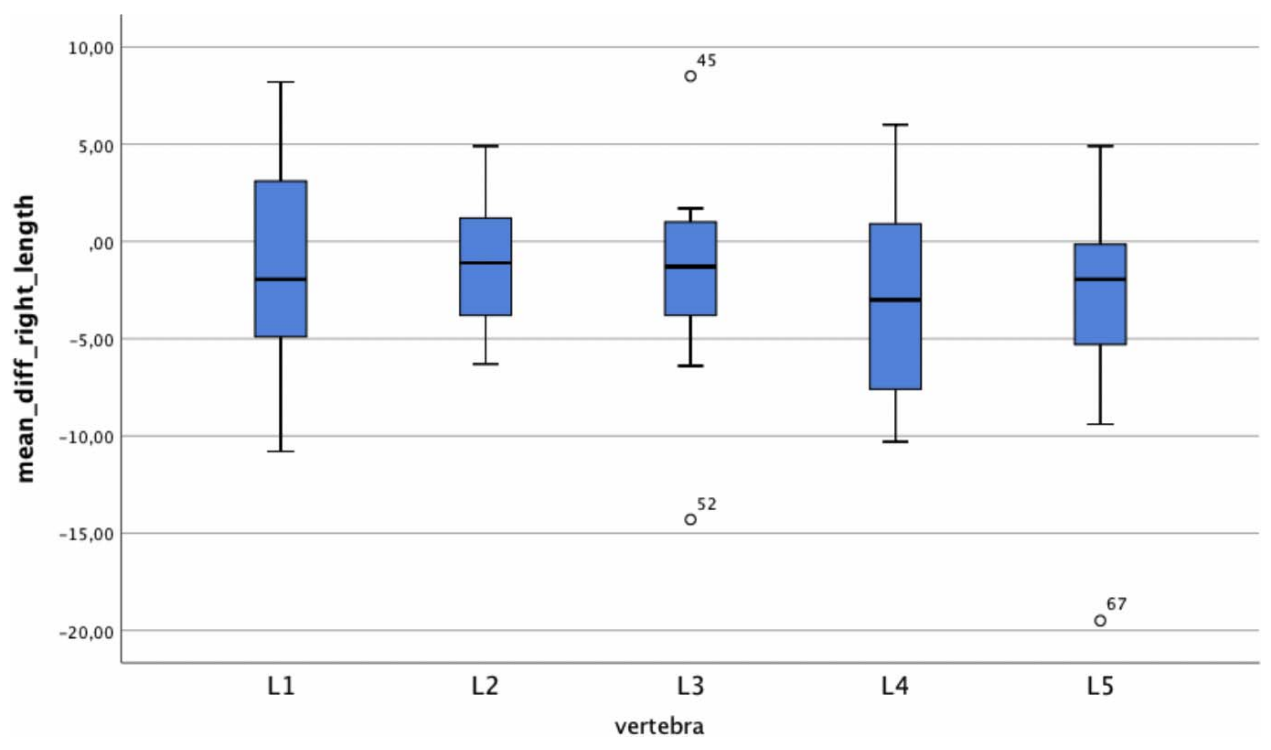

however, we found no significant difference in diameter measurements at the right pedicle. Since the vertebral bodies are axisymmetric, an explanation is difficult and possibly a consequence of the small number of cases. It is also possible that the differences in the measurements could be due to the different presentation of spondylarthrotic changes in CT and MRI images. We aimed to take such potential confounders into account by adjusting for gender and spondylarthrotic changes in our analyses, but no significant influence was found.

As we expected from clinical experience, CTbased measurements of screw length were significantly lower compared to MRI. However, given that screw length can be easily measured intraoperatively, preoperative planning is not so important. More important is good diameter planning. ${ }^{10-12,14}$ From a practical point of view, every surgeon

Table 6. Mean difference in diameter (left pedicle).

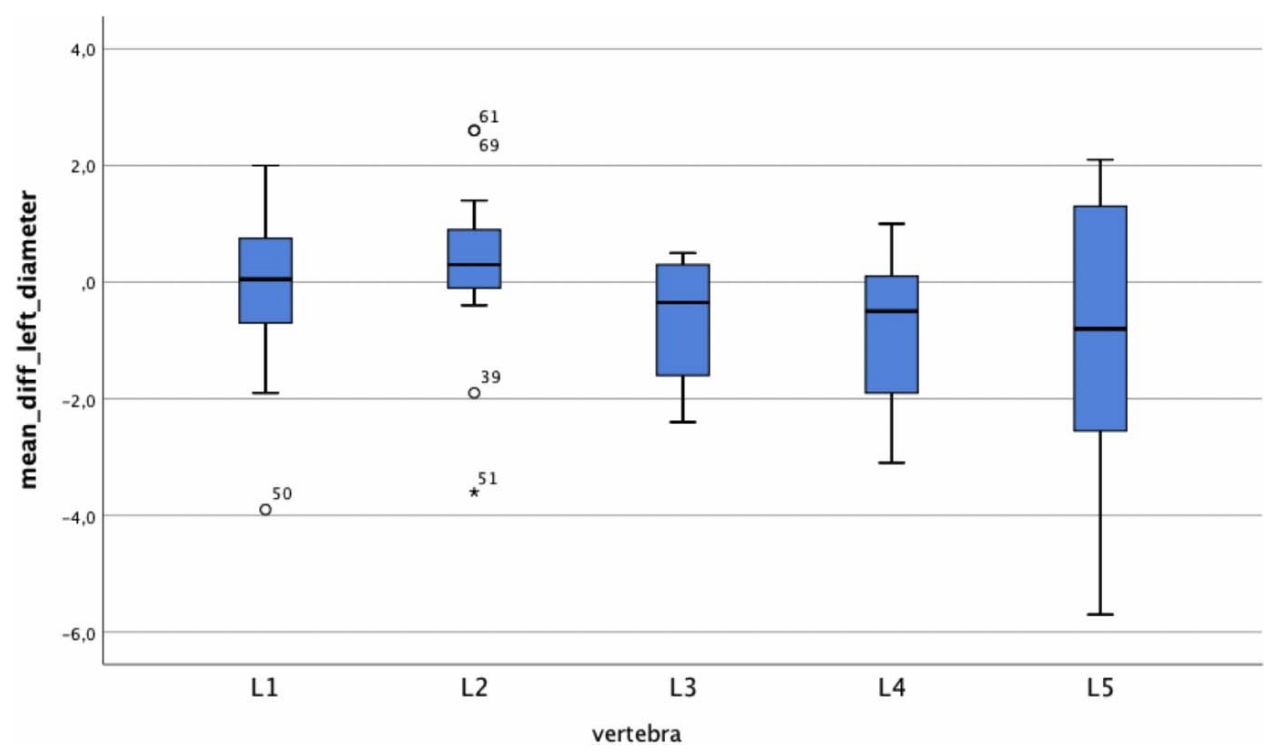


Table 7. Mean difference in diameter (right pedicle).

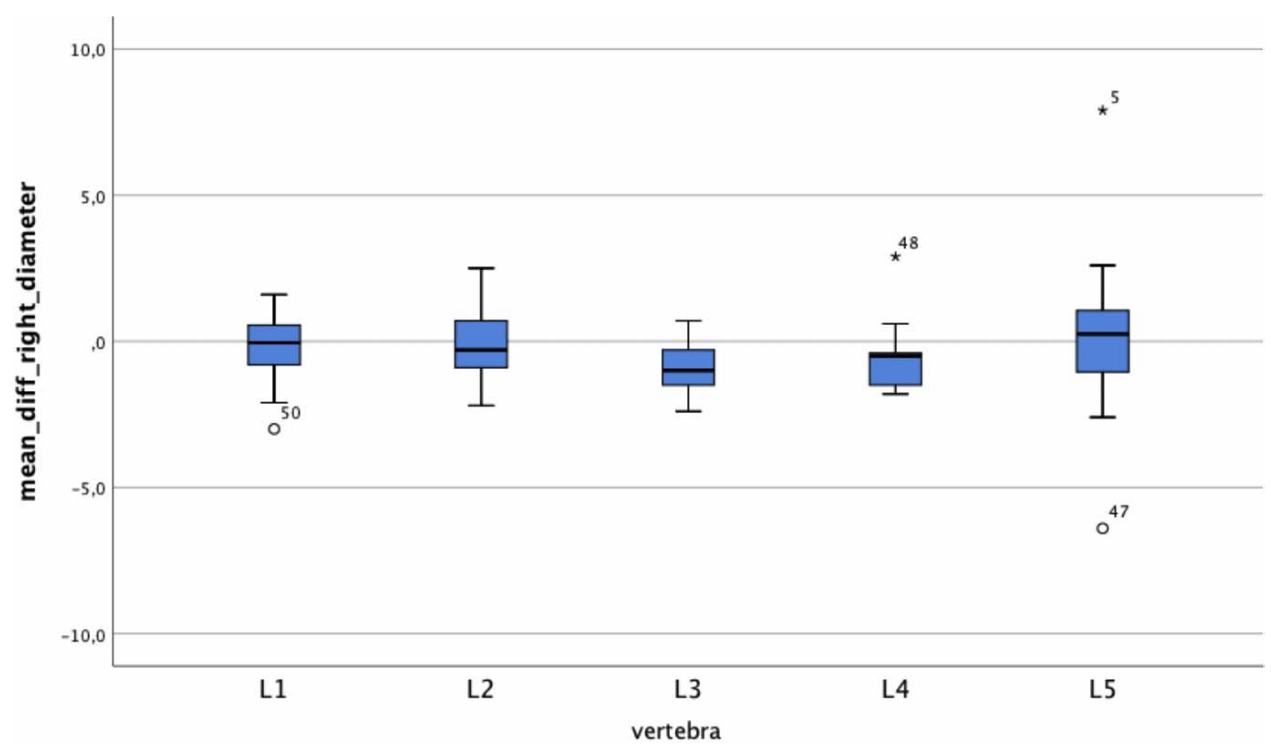

should know the sizes of the implants that are likely to be needed, as the diameter is difficult to estimate intraoperatively. Implants of the wrong size can ultimately lead to unstable fixation ${ }^{10}$ or may lead to pedicle fracture or damage to the nerves and vessels. ${ }^{7,11,15}$ For osteoporotic fractures, which are commonly stabilized using cement augmentation, pedicle fractures may lead to cement leaks into the spinal canal. Furthermore, the surgeon should be aware preoperatively of whether sufficient implant material of the correct length and diameter for a stable osteosynthesis is in stock.

One might be willing to settle for preoperative MRI in the run-up to an operation and refrain from further precise bone imaging to, for example, save radiation or because the MRI sufficiently clarifies the indication for surgery. From our point of view, this intent may be warranted from patient safety aspects. With regard to unnecessary costs and radiation, any unnecessary imaging should be avoided. However, this study suggests that the derived screw dimensions may not correspond to the desired implants, relying solely on MRI diagnosis.

Taking the CT scan as the gold standard, on average the length measurements via MRI are about 1.9-2.1 mm longer, and the diameters in the CT scan are about $0.4-0.5 \mathrm{~mm}$ wider. Therefore, the avoidance of a CT scan with the goal of patient safety may save radiation and costs but can ultimately lead to increased risk.

This study does have several limitations. For imaging, we could not use the same devices in all patients, both for the MRI examination and for the CT examination. The MRI resolution therefore

Table 8. $\quad P$ value univariate analysis of variance (adjusting for age, sex, arthrosis, and combined).

p-value univariate ANOVA (adjusting for age, sex, arthrosis and combined)

\begin{tabular}{l|l|l|l|l}
\hline Factor & $\begin{array}{l}\text { Pedicle length } \\
\text { left }\end{array}$ & $\begin{array}{l}\text { Pedicle length } \\
\text { right }\end{array}$ & $\begin{array}{l}\text { Pedicle } \\
\text { diameter left }\end{array}$ & $\begin{array}{l}\text { Pedicle } \\
\text { diameter right }\end{array}$ \\
\hline age & 0.662 & 0.035 & 0.854 & 0.143 \\
\hline sex & 0.106 & 0.322 & 0.897 & 0.349 \\
\hline spondylarth. & 0.790 & 0.015 & 0.361 & 0.124 \\
\hline sex*spondylarth & 0.086 & 0.535 & 0.063 & 0.129 \\
\hline R-Square & 0.052 & 0.103 & 0.172 & 0.096 \\
\hline
\end{tabular}


Table 9. Interaction plot for length (left pedicle) $(P=.086)$.

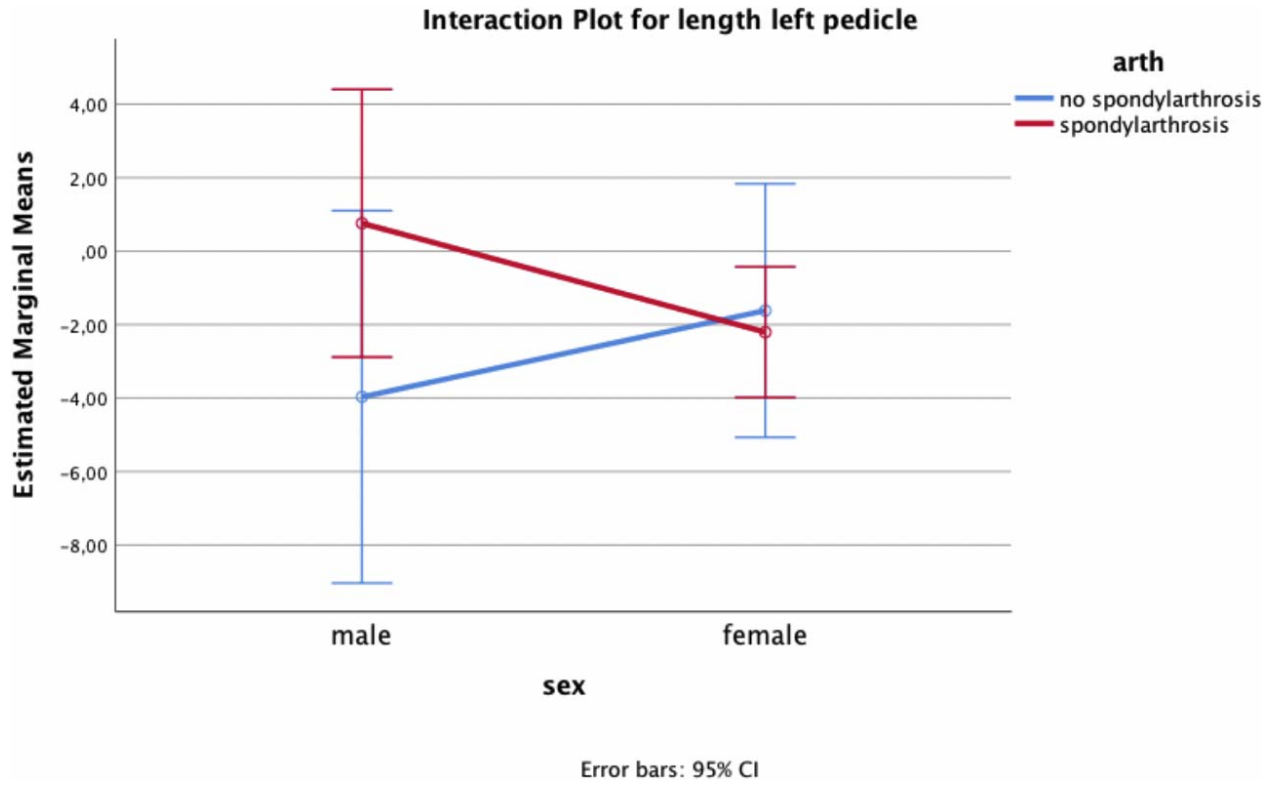

varies from 1.5 to 3 Tesla. Many patients reach our clinic with imaging already made elsewhere.

Another limitation - the difference in the sectional planes between MRI and CT-is an inherent technical hurdle. In CT imaging, each vertebral body can be freely adjusted in 3-dimensional space. Thus, the cutting planes can be aligned exactly with the endplates and pedicle axis. In order to obtain exactly comparable measurement levels, it is desirable to be able to proceed in the same way with the data obtained from the MRI. But to approximate the actual cutting plane to the desired sectional plane in MRI, the whole geometry has to be tilted to put the image in the right place. To overcome this

Table 10. Interaction plot for length (right pedicle) $(P=.535)$.

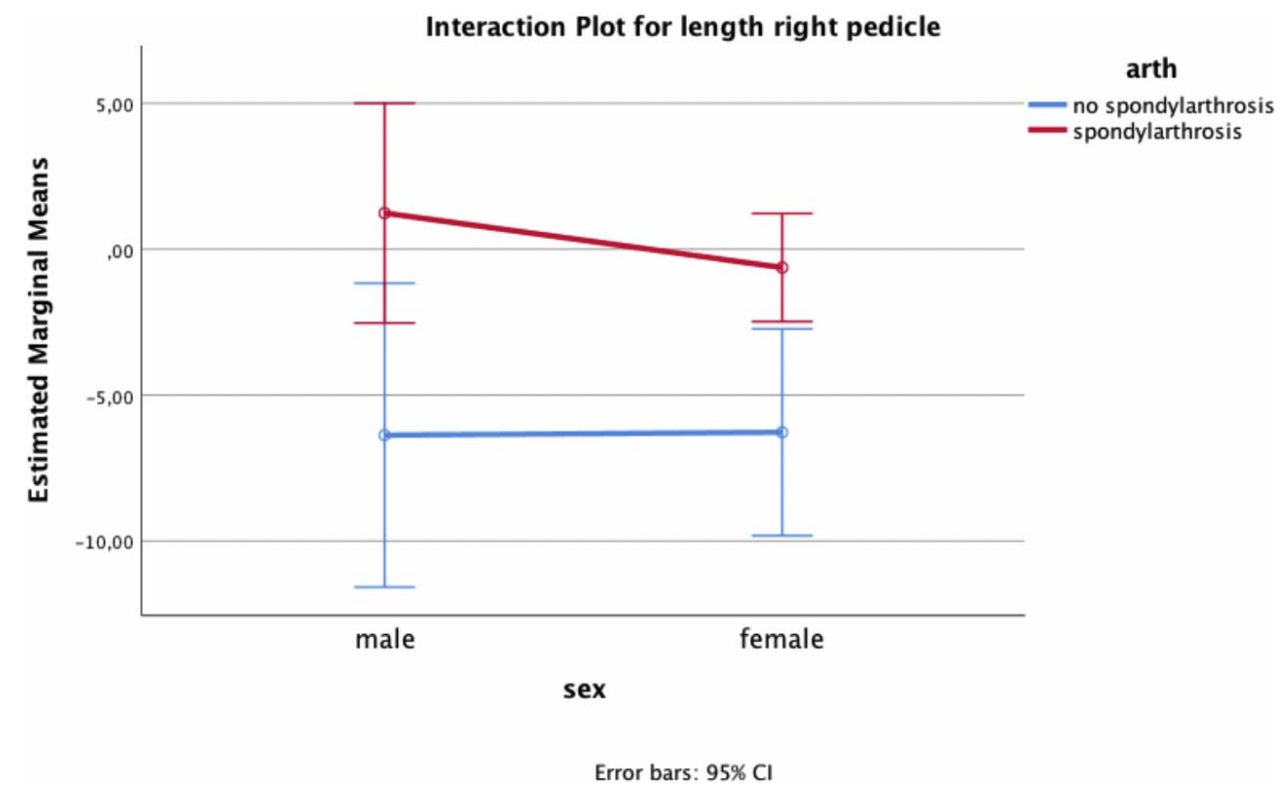


Table 11. Interaction plot for diameter (left pedicle) $(P=.063)$.

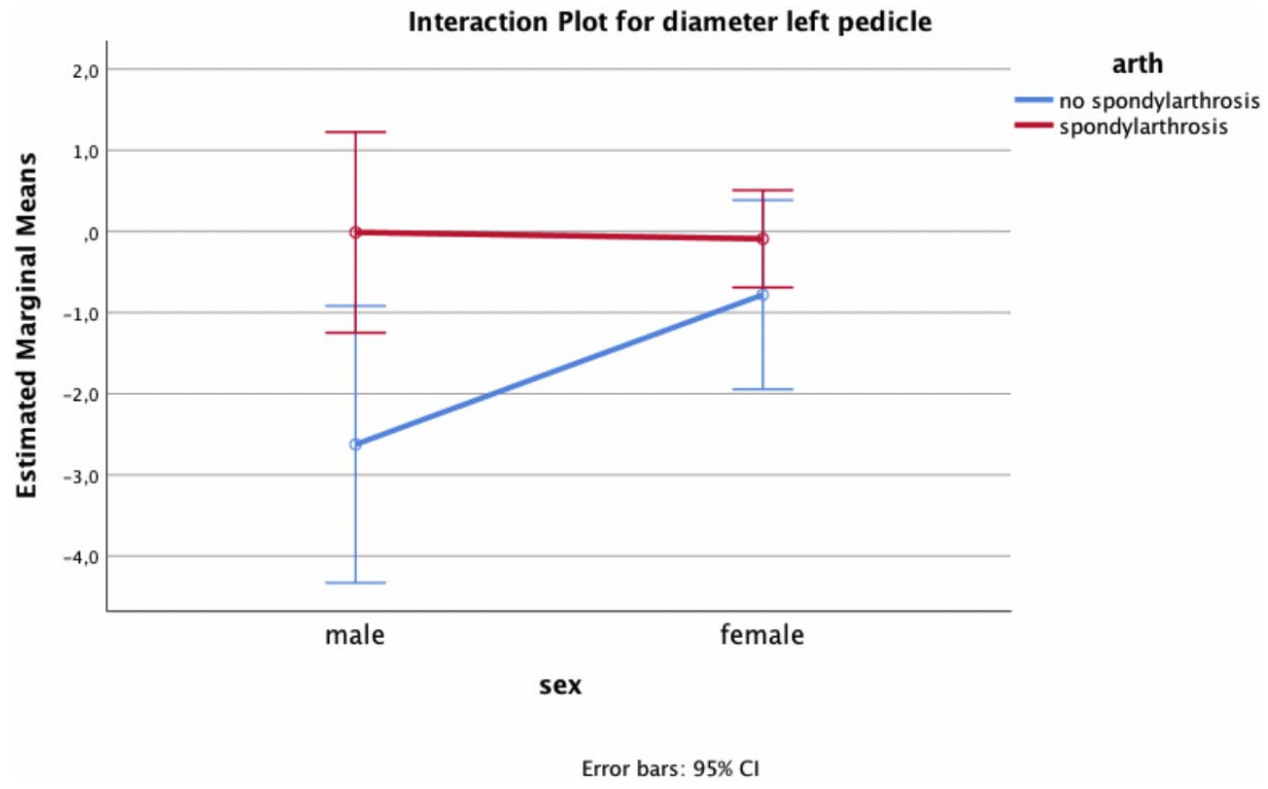

limitation, we performed the measurements over several lumbar vertebral bodies of the same patient. In this way, we were able to reduce the number of different examinations and increase the number of comparable pedicle measurements. Furthermore, our research reflects the current limitations of MRI imaging under realistic clinical conditions.
We also note that our findings cannot be directly translated to the thoracic spine, as we measured only lumbar bodies. Finally, we did not correlate the findings with actual implants or implant failure in our study, which should be the focus of future research.

Table 12. Interaction plot for diameter right pedicle $(P=.129)$.

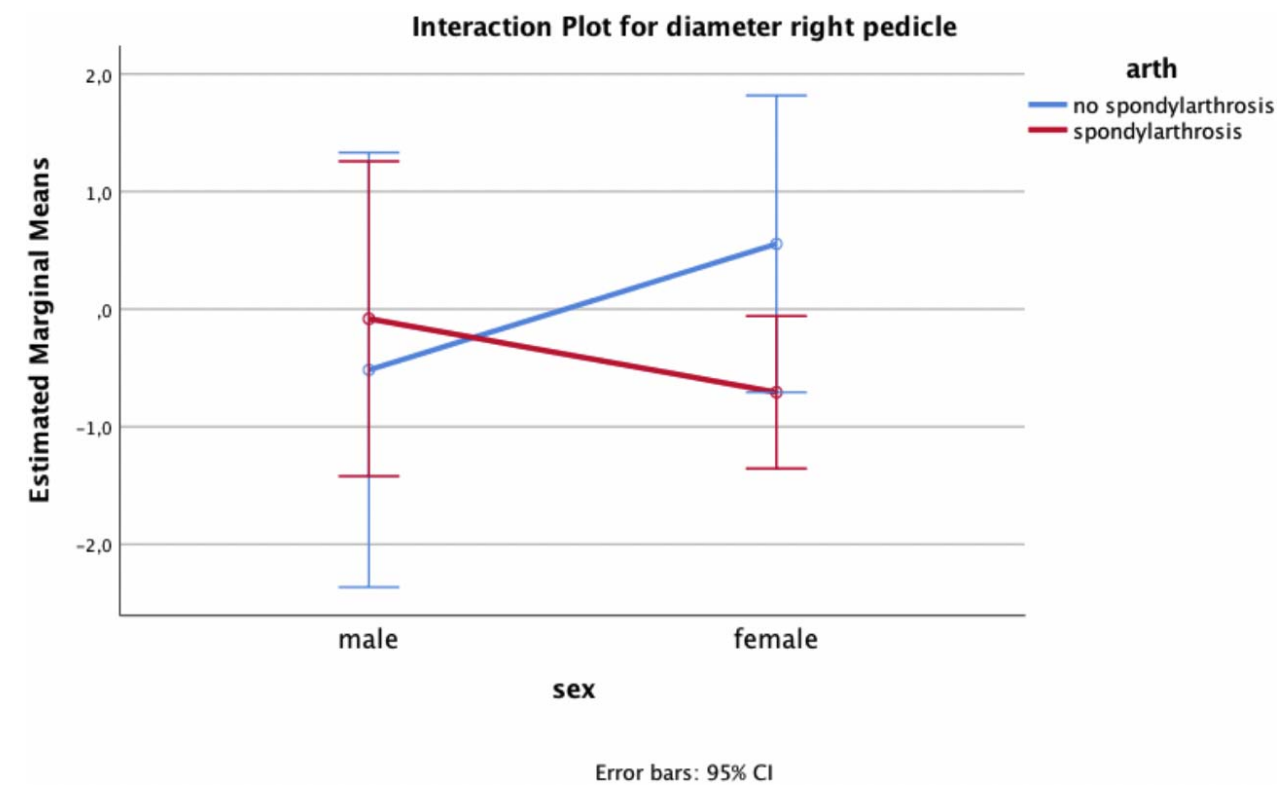




\section{CONCLUSIONS}

Pedicle screw planning measurements were more accurate using CT images compared to MRI images. When using MRI images, the surgeon should be aware of the differences in screw length and diameter compared to $\mathrm{CT}$ in order to avoid intra- and postoperative risks.

\section{REFERENCES}

1. Wood KB, Li W, Lebl DS, Ploumis A. Management of thoracolumbar spine fractures. Spine J. 2014;14(1):145-164.

2. Spiegl UJ, Josten C, Devitt BM, Heyde C-E. Incomplete burst fractures of the thoracolumbar spine: a review of literature. Eur Spine J. 2017;26(12):3187-3198.

3. Bliemel C, Lefering R, Buecking B, et al. Early or delayed stabilization in severely injured patients with spinal fractures? Current surgical objectivity according to the Trauma Registry of DGU: treatment of spine injuries in polytrauma patients. $J$ Trauma Acute Care Surg. 2014;76(2):366-373.

4. Schnake KJ, Schaeren S, Jeanneret B. Dynamic stabilization in addition to decompression for lumbar spinal stenosis with degenerative spondylolisthesis. Spine. 2006;31(4):442-449.

5. Guigui P, Ferrero E. Surgical treatment of degenerative spondylolisthesis. Orthop Traumatol Surg Res. 2017;103(1):S11-S20.

6. Yavin D, Casha S, Wiebe S, et al. Lumbar fusion for degenerative disease: a systematic review and meta-analysis. Neurosurgery. 2017;80(5):701-715.

7. Liu H, Chen W, Liu T, Meng B, Yang H. Accuracy of pedicle screw placement based on preoperative computed tomography versus intraoperative data set acquisition for spinal navigation system. J Orthop Surg. 2017;25(2):230949901771890.

8. Galbusera F, Lovi A, Bassani T, Brayda-Bruno M. MR Imaging and radiographic imaging of degenerative spine disorders and spine alignment. Magn Reson Imaging Clin $N$ Am. 2016;24(3):515-522.

9. Kanna RM, Kamal Y, Mahesh A, Venugopal P, Shetty AP, Rajasekaran S. The impact of routine whole spine MRI screening in the evaluation of spinal degenerative diseases. Eur Spine J. 2017;26(8):1993-1998.

10. Bianco R-J, Arnoux P-J, Wagnac E, Mac-Thiong J-M, Aubin C-É. Minimizing pedicle screw pullout risks: a detailed biomechanical analysis of screw design and placement. Clin Spine Surg. 2017;30(3):E226-E232.

11. Lee J, Kim S, Kim YS, Chung WK. Optimal surgical planning guidance for lumbar spinal fusion considering operational safety and vertebra-screw interface strength: optimal surgical planning guidance for lumbar spinal fusion. Int J Med Robot. 2012;8(3):261-272.

12. Cho W, Cho SK, Wu C. The biomechanics of pedicle screw-based instrumentation. J Bone Joint Surg Br. 2010;92B(8):1061-1065.

13. Matsukawa K, Yato Y, Hynes RA, et al. Comparison of pedicle screw fixation strength among different transpedicular trajectories: a finite element study. Clin Spine Surg. 2017;30(7):301-307.
14. Matsukawa K, Yato Y, Imabayashi H, et al. Biomechanical evaluation of fixation strength among different sizes of pedicle screws using the cortical bone trajectory: what is the ideal screw size for optimal fixation? Acta Neurochir (Wien). 2016;158(3):465-471.

15. Newell R, Esfandiari H, Anglin C, Bernard R, Street J, Hodgson AJ. An intraoperative fluoroscopic method to accurately measure the post-implantation position of pedicle screws. Int J Comput Assist Radiol Surg. 2018;13(8):12571267.

16. Paik H, Kang DG, Lehman RA, Gaume RE, Ambati DV, Dmitriev AE. The biomechanical consequences of rod reduction on pedicle screws: should it be avoided? Spine J. 2013;13(11):1617-1626.

17. Sarwahi V, Amaral T, Wendolowski S, et al. MRIs are less accurate tools for the most critically worrisome pedicles compared to CT scans. Spine Deform. 2016;4(6):400-406.

18. Guarnieri G, Izzo R, Muto M. The role of emergency radiology in spinal trauma. Br J Radiol. 2016;89(1061):20150833.

19. Chidambaram S, Goh EL, Khan MA. A meta-analysis of the efficacy of whole-body computed tomography imaging in the management of trauma and injury. Injury. 2017;48(8):1784-1793.

20. Jiang L, Ma Y, Jiang S, et al. Comparison of whole-body computed tomography vs selective radiological imaging on outcomes in major trauma patients: a meta-analysis. Scand $J$ Trauma Resusc Emerg Med. 2019;22(1):54. doi:10.1186/s13049014-0054-2

21. Bredow J, Boese CK, Werner CML, et al. Predictive validity of preoperative CT scans and the risk of pedicle screw loosening in spinal surgery. Arch Orthop Trauma Surg. 2016;136(8):1063-1067.

Disclosures and COI: All authors disclose any financial and personal relationships with other people or organizations that could inappropriately influence their work. There are no conflicts of interest. Ethics Committee of the MHH: An assessment by the ethics committee and the in-house data protection officer is available. No concerns were raised.

Corresponding Author: Tarek Omar Pacha, MD, Trauma Department, Hannover Medical School,Carl-Neuberg-Str.1/ 30625/Hanover, Lower Saxony, Germany. Phone: +49151-46250892; Email: OmarPacha.Tarek@mh-hannover.de.

Published 11 November 2020

This manuscript is generously published free of charge by ISASS, the International Society for the Advancement of Spine Surgery. Copyright (C) 2020 ISASS. To see more or order reprints or permissions, see http://ijssurgery.com. 